\title{
Instagram as a Medium for Teaching and Learning English: A Qualitative Systematic Review
}

\author{
Daviq Rizal ${ }^{1}$ and Resti Farikhah $\mathbf{Z}^{2}$ \\ ${ }^{1,2}$ Universitas Islam Negeri Walisongo, Indonesia \\ (daviqr@walisongo.ac.id)
}

\begin{abstract}
The purpose of the research paper was to explore the use of Instagram as social media in learning English skills such as reading, speaking, listening, and writing skills. Using a qualitative systematic review, the researchers searched 24 journal articles on the use of Instagram in English language teaching and learning in Google Scholar for data saturation and analysis. This entailed reading and rereading the manuscripts, followed by coding the data, with each pass enhancing and modifying the codes. The study showed that Instagram could be used as a teaching tool for English language learners and helpful in their English learning. Teachers should use the chance to make the most of this advancement and start using Instagram in the classroom. Because Instagram is one of the most popular social media platforms, students can practice writing about their daily activities and provide feedback on their classmates' writing. According to this study, using Instagram to teach students how to write descriptive writings is beneficial. Furthermore, the experimental students given Instagram media therapy outperformed control students. The results can be significant inputs for English language teachers to use Instagram in real classrooms.
\end{abstract}

Keywords: Instagram; English learning; social media application; teaching media.

Numerous studies have been conducted on the use of Instagram in English language teaching and learning. However, a qualitative systematic review of the scientific articles on Instagram as a medium in English language teaching and learning has not been done yet. Sari \& Wahyudin (2019) explained that Instagram could be used as an effective instructional media and a language learning tool outside the classroom. Studies on using Instagram in EFL classrooms show that it helps the learning process in enhancing subject learning.

Sari \& Wahyudin (2019) further described that the widespread of social 
networking sites could be optimized as the modern teaching media. Through Instagram, the teacher and students can do photosharing and video-sharing. It is assumed beneficial as an effective educational experience for language classrooms since it may create a meaningful learning environment.

Learning a new language requires the acquisition of four skills in general. First, it is essential to learn how to communicate effectively in English by speaking, reading, listening, and writing. Second, writing requires practice and knowledge of three other language skills: listening, reading, and speaking. Third, for the reader to grasp their writing, they must convey their thoughts and feelings creatively (Baqiatus Sallamah \& Husein As Sabiq, 2020).

It is widely accepted that teaching English skills in an EFL classroom is a complex endeavor. First, teachers educate pupils on how to write effective essays; a time-consuming, multi-step process is required. To educate students on reading, listening, and speaking skills, teachers have employed a range of approaches and strategies, both traditional and modern. However, only a small amount of research has been conducted to demonstrate its utility, particularly in the case of technologyenhanced education (Rinda, Novawan, \& Miqawati, 2018).

The era of globalization and popular culture is becoming increasingly significant in all circles. The phenomenon of gadget obsession is becoming more popular in many countries, particularly in Indonesia (Christanty, Bestari, Faiza, \& Mayekti, 2020). Lecturers' professional development and the addition of media/ways to their instruction can benefit from social networking activities. The professors will be in close contact with their students. They will be interactive in order to improve the English students' skills. Students and professors can plan exercises such as writing skill development, grammatical comprehension, and so on.

Instagram was chosen as a good tool for learning a foreign language, especially
English, because of its excellent characteristics. It confirms that Instagram fosters a sense of community and facilitates meaningful communication among students (Rinda et al., 2018). Use social media Instagram is a messaging 'platform (app) that allows users to engage with a larger audience by posting photographs or videos, as well as additional features like DM (direct message), comments, and love. Instagram (also known as IG or Insta) is a picture and video-sharing software that allows users to shoot images, record videos, apply digital filters, and publish their creations on a variety of social media platforms, including Instagram's own. Many Instagram accounts currently exist that provide not only photographs and videos but also particular information regarding English stuff.

As a result of this, it can be stated that today's kids have access to a wealth of technology In terms of user numbers, Instagram has a large following and is wellknown around the world. As of April 2012, less than two years after its introduction, there were more than 100 million active users. It grew in popularity, with over 600 million users as of April 2017. Instagram currently has 90 million monthly active users. (Soviyah \& Etikaningsih, 2018)

Instagram was first created in 2010 as a photo-sharing platform, but as time went on, other capabilities such as video, texting, and story sharing were introduced, considerably contributing to its growth. (Erarslan Yabanci Diller Egitimi Bolumu \& Dili Egitimi Anabilim Dali Bask, 2019). As a result of these factors, it is reasonable to conclude that social media is a useful tool for teachers to employ in the classroom (Kurniati, 2021). Teachers and students have different roles in supporting learning on Instagram. Teachers must provide appropriate guidance and feedback to successfully use online communities. Students engage in self-authorship by generating materials, which function as fundamental for learning. These ways help to increase students' interest and allow them to be more active in 
their own learning process (Sari \& Wahyudin, 2019). Teachers can use a variety of activities to incorporate Instagram into their classes. Instagram photographs and videos serve as writing prompts, encouraging students to write their own sentences beneath the posted content. (Abdulaziz Al Fadda, 2020) Although Instagram and Snapchat are popular social media sites, the article contends that they are primarily utilized for informal purposes rather than learning complicated information such as English speaking abilities since they generate unfavorable attitudes and impressions due to the slang phrases employed. (AlGhamdi, 2018). the study is to find out the effect of social media and students' attitudes in learning English skills like reading, speaking, listening, and writing, and this research will focus on the Instagram application.

Instagram was used as a learning tool to create content for one speaking exercise and two writing activities to reinforce speaking, grammar, writing, and vocabulary skills. Instagram helps to revolutionize the language classroom by allowing students to generate ideas for writing exercises using contextually relevant content while also providing them with a fun learning experience. This experiment resulted in a few teaching ideas to ensure the better incorporation of Instagram as a learning tool in language schools. (Erarslan, 2019)

Perusing content shared by other educators was the most popular reason for their utilization. We talk about the implications of our final findings for educators' and teacher educators' work in the digital era, as well as the future of research on educators professional usage of social media (Sallamah \& As Sabiq, 2020). Studies on social media in ESL classrooms have been widely conducted throughout.

The studies examine the use of social media technologies such as Facebook, blogs, Twitter, and Instagram in language learning classrooms via cellphones, a phenomenon is known as mobile learning. (Gonulal, 2019) examined the efficacy of cell phone use for synchronous and asynchronous engagement, as well as the development of students' listening and speaking abilities. The author found that mobile devices are capable of successfully supporting collaborative speaking and listening activities. Similarly, Lan, Sung, and Chang (2009) asserted that mobile devices enable students to construct collaborative learning environments. Additionally, they increase their motivation to read. Borau et al. (2009) demonstrated the benefits of these gadgets, which enable students to participate actively in English language 'creation' and therefore further develop their communicative ability (Gonulal, 2019).

After discussing Instagram and the activities associated with it, it can be stated that Instagram has a favorable effect on students' language skills. It is an effective educational tool since it enables students and teachers to communicate easily outside of office hours and the classroom. Utilizing Instagram enables students to develop ideas through contextually relevant content and provides them with an enjoyable learning experience. As a result, teachers can use Instagram to build engaging exercises for teaching English. Finally, it should be stressed that using Instagram in foreign language study may be a useful and innovative tool when students and teachers utilize it responsibly for instructional purposes (Aloraini, 2018).

Students and teachers can save time by using Instagram English teaching pages, which give them options for dealing with shortfalls in various situations (Kurniati, 2021). Utilizing Instagram as a mobile language learning tool is not without its drawbacks. One disadvantage frequently mentioned, particularly in qualitative data, is the frequency of informal language on Instagram (Gonulal, 2019).

Students' reactions to using Instagram as a medium in class are both interesting and useful. Students' replies are intriguing because Instagram is well-known and provides quick access to the lesson's source. Then 
there's Instagram, which is beneficial since it encourages kids to be more creative while also making it simple to find sources (Efendi, 2019). Instagram could be one of the options for supporting the practice of language teaching at the university level(Agustin \& Ayu, 2021). The English slangs were produced and posted on Instagram by the participants primarily to express self-identity and emotional sensations (Kurniati, 2021).

Teaching English speaking skills, according to most English teachers, is extremely difficult. Teachers do not ask students to practice English in real life, rather than just in the classroom. Practicing is essential since it is crucial to bring English closer to the kids in order to make it a habit. Apart from Instagram, using social media for English improvement can be explored as long as the medium is straightforward to identify and utilize for the students. Instagram can also be used to help pupils improve their other talents. (Nurhikmah, 2021) Instagram users post images with bragging, complaint, or humblebragging as a politeness strategy to mitigate the effect of their presentation to create positive and boastful disclosures (Chalak, 2021) elements that influence a student's ability to write The children lacked vocabulary, linguistic skills, and mechanics, making it difficult for them to express themselves. Their writing contained numerous errors. They made grammatical errors and misapplied word forms in their vocabulary (Rosyida \& Seftika, 2019).

\section{Method}

Unique references were retrieved, while the abstracts were reviewed using the search parameter. This used 24 journal references, and If the references were not accounts of metasynthesis investigation, they were removed from consideration (Finfgeld-Connett, 2014a). Each randomly chosen article was first read, with key information underlined and collected. This project's literature review began with a study of key articles (Finfgeld-Connett \& Johnson, 2013)
In inductive analysis, qualitative systematic reviewers begin a review with few preconceptions about a topic and no coding scheme in mind. Instead, they begin their analysis by looking at the raw data (FinfgeldConnett, 2014b). This study extended similar approaches to prominent social media platforms, including Instagram, with Instagram being of special relevance because visuals are processed differently than plain text. (Messner, Medina-Messner, \& Guidry, 2016). From all the research that the researcher is getting much information through the implementation of Instagram as a media teaching in EFL class, but whatever this method also needs some investigation the researcher needs the analytic categories. The final categories of technology experiences were formed by combining and contrasting the analytic categories. (Lai, $\mathrm{Hu}$, \& Lyu, 2018) in March 2021, General Practice Society started creating daily MCQs on Instagram (@qubgpsociety), posting these as 'Instagram Stories.' (Gulati, Reid, \& Gill, 2020) and this activity gives us an example of implementing Instagram as a teaching media.

A thematic analysis method concentrates on both semantic (surface meanings) and latent (underlying ideas or assumptions) components of the data. This entailed reading and re-reading the manuscripts, followed by iteratively coding the data, with each pass enhancing and modifying the codes. (Lambton-Howard, Kiaer, \& Kharrufa, 2020) following through the first stage of planning, exploring, analyzing, and reflecting, and the second stage of planning, acting, observing, and reflecting. Then, regarding data collection, due to the restrictions imposed by the pandemic and the consequent difficulties we had, we decided to treat our materials design process as a single case study.

\section{Results and Discussion}

The first research question was on whether different user profiles would emerge when utilizing the application as a teaching 
tool. Instagram does provide the ability to combine photographs and text, which can be very useful. It is also a means to make learning more enjoyable and relatable for students. In this application that many slang or poor English use is very popular on Instagram; it may not be the best platform for improving English skills, particularly grammar understanding, but it can be a solution to help the student increase their ability in English skills.

Most citizens are using this platform in their daily activity, and we found about the English learners that use these tools to help them in understanding the materials, the majority of the followers were more interested in the simple structure instructions than the complicated structure instructions. When a learner's processing capabilities come over complicated structures, he or she is less likely to participate actively online, maybe due to the higher processing demands of understanding the more complex structures.

Most people use Instagram as a tool in their learning of the English language that more interested in simple structure instruction. According to Brebara (2018), 88 percent of 152 graduate students in the Czech Republic found Instagram to be helpful in their English learning. Instagram can be used for a variety of purposes. Students might use their writing skills to add text to the "title" part and provide feedback in a comment column before sharing their photographs or videos.

In this research the find Instagram is about more than selfies, likes/comments, and reposts. Teachers should use the chance to make the most of this advancement. Starting to use Instagram in the classroom is a fantastic concept. Instagram has the potential to be a fantastic teaching tool that makes learning fascinating, engaging, and perceptive. In accordance with the coursebook, he created posts and Instagram stories based on four skills and linguistic areas. Short films and pronunciation exercises with questions in the comments section were posted on a regular basis for listening reasons. In addition, the positions asked students to undertake various tasks (such as conducting a job interview with two classmates) using videos in order to strengthen their speaking skills as well as their listening skills (Erarslan, 2019), and then students might use Instagram to practice writing about their daily activities. Technology aids in improving educational benefits, as evidenced by the usage of Instagram as a technology for uploading students' writing. Then, Instagram is one of the efficient tools or media in teaching English skills because most students often use social media in their activities. Every student makes use of this site on a daily basis. Instagram is widely used by students. As a result, now is a fantastic time to put it to use.

Instagram, on the other hand, has grown in popularity in recent years as one of the most widely used social media sites, despite the fact that there is little research exploring its usefulness as a language learning platform. Instagram, on the other hand, has grown in popularity in recent years as one of the most important social media sites, despite the fact that there is little research exploring its usefulness as a language learning platform. Throughout the teaching and learning process, the pupils demonstrated their curiosity. During the teaching writing process, the majority of them appreciated actively participating in expressing their ideas. They were both working on Instagram and giving each other feedback on their friends' writing.

Table 1. shows that the students are most likely to adopt metacognitive methods. The metacognitive strategies are preferred by 34 out of 80 pupils or 43 percent. Social strategies come in second with $21 \%$ of the vote. Compensation and memory are the third and fourth most popular tactics among students, with 14 percent and 13 percent, respectively. Affective and cognitive techniques are the least typically used by pupils, accounting for $5 \%$ and $4 \%$, respectively.

Another key conclusion is that the less successful English learners do not employ 
Table 1. Metacognitive Strategies

\begin{tabular}{lcr}
\hline Strategies & Number of Students & $\%$ \\
\hline Memory Strategies & 10 & 13 \\
Cognitive Strategies & 3 & 4 \\
$\begin{array}{l}\text { Compensation Strat- } \\
\text { egies }\end{array}$ & 11 & 14 \\
$\begin{array}{l}\text { Metacognitive Strat- } \\
\text { egies }\end{array}$ & 34 & 43 \\
Affective Strategies & 5 & 5 \\
Social Strategies & 17 & 21 \\
\hline Total & 80 & 100 \\
\hline
\end{tabular}

a variety of learning tactics. The interview questions were answered significantly more thoroughly by the successful students. They claim to employ more tactics than less successful students. The conclusions of the sixteen personal interviews corroborate the findings of the SILL survey. This also contradicts the conclusions of survey data from less favored high schools. In terms of the technique indicated in the interview, the data revealed that the strategies used by students to enhance their English range from one student to the next and from one skill level to the next.

In general, the experimental group's results were higher than the control group's scores. It is demonstrated by the experimental group's post-test mean score, which was higher than the control group's post-test mean score at 80.04 and 76.68, respectively. As a result, it can be stated that using Instagram to teach students how to write descriptive writings is beneficial. The experimental students who were given Instagram media therapy outperformed the control students who were not given Instagram media treatment.

By using Instagram as a tool for learning a foreign language, we can utilize many activities that can be done through this platform as speaking activity, reading activity, writing activity, and listening activity. From all those activities can be seen that Instagram is a useful tool to be used in teaching languages because Instagram has many advantages in the teaching-learning process, especially in the English learning process. First, Instagram helps to increase communication skills and provides a back door for shy learners. Second, Instagram is based on the written word, and it is a wonderful tool for having writing skills. The third Instagram do the collaboration and peer feedback among students, for the fourth Instagram promotes interpersonal skills, and finally, this online tool invites teachers and students to a single platform where they can engage in various fun activities and engagements.

Instagram has various features to increase the ability such as IG live feature, Instagram group, corrective feedback in the Instagram caption, students reported a meaningful classroom setting, pleasant learning exercises, peer-review activity, effective corrective feedback, and finally, writing ability improvement through Instagram features such as live videos, Instagram groups, and caption writing. It is suggested that teachers use social media to successfully mediate online learning.

By utilizing Instagram as a teaching media, its can make the student more confident in writing by practicing writing an Instagram caption; in this session, they try to write sentences confidently, so they got improving vocabulary, so they can do peer learning by giving responses to each other in the comment box or giving expression in the feature of Instagram application

\section{Conclusion}

Instagram is a popular social networking platform among youngsters due to its numerous fascinating features. Because many people enjoy using social media, researchers can obtain multiple accounts that can be highly valuable in learning English. Instagram has been found to be an efficient tool for language learning. According to the findings of this study, students believe that social media platforms, notably Instagram in this case, maybe used 
specifically for educational purposes. Lack of privacy, restrictions on personal use, a lack of structure in learning possibilities, and the presence of grammatical and spelling faults in public messages across the Internet are all disadvantages of this platform.

Students and teachers can save time by using Instagram English teaching pages, which give them options for dealing with shortfalls in various situations. They can provide the option to have a class with native teachers, and they can also boost learners' motivation by presenting materials in a variety of ways. (Rajani \& Chalak, 2021). The data revealed that the tactics used by students to improve their English vary from student to student and skill level to skill level. While using Instagram to teach writing in an EFL classroom is highly recommended, there are several problems that must be addressed and overcome. Students' interaction, students' knowledge of technology, the teacher's function, and the institution's internet access must all be enhanced in order to maximize the institution's capabilities. The nature of English instruction in higher education is characterized by its intimate ties to specific academic and professional settings. The nature of English instruction in higher education is characterized by its intimate ties to specific academic and professional settings.

Teachers can manage classroom discussions about the topic of students' book trailers after all of the students' projects have been posted. The teacher can use Instagram to teach the fundamental English materials, like speaking, reading, writing, and listening skills.

\section{References}

Abdulaziz Al Fadda, H. (2020). Determining How Social Media Affects Learning English: An Investigation of Mobile Applications Instagram and Snap Chat in TESOL Classroom. Arab World English Journal, 11(1), 3-11. https:// doi.org/10.24093/awej/vol11nol.1
Agustin, R. W., \& Ayu, M. (2021). The Impact of Using Instagram for Increasing Vocabulary and Listening Skill. Journal of English Language Teaching and Learning (JELTL) 2(1). 1-7

AlGhamdi, M. A. (2018). Arabic Learners' Preferences for Instagram English Lessons. English Language Teaching, 11(8), 103. https://doi.org/10.5539/elt. v11n8p103

Chalak, Azizeh. (2021). Pragmatics of SelfPraise and Self-Presentation by Iranian EFL Learners on Instagram. 25. 1-16.

Christanty, A., Bestari, Y., Faiza, D., \& Mayekti, M. H. (2020). Instagram Caption As Online Learning Media on the Subject of Extended Writing During Pandemic of COVID-19. Surakarta English and Literature Journal, 3(1), 9-12

Efendi, Herman (2019) Using Instagram as instructional media to develop students' Higher-Order Thinking in teaching English speaking. Undergraduate thesis, UIN Sunan Ampel Surabaya

Erarslan, A. (2019). Instagram as an Education Platform for EFL Learners. TOJET: The Turkish Online Journal of Educational Technology, 18(3), 54-69

Finfgeld-Connett, D. (2014a). Metasynthesis findings: Potential versus reality. Qualitative Health Research, 24(11), 1581-1591. https://doi. org/10.1177/1049732314548878

Finfgeld-Connett, D. (2014b). Use of content analysis to conduct knowledge-building and theory-generating qualitative systematic reviews. Qualitative Research, 14(3), 341-352. https://doi. org/10.1177/1468794113481790

Finfgeld-Connett, D., \& Johnson, E. D. (2013). Literature search strategies for conducting knowledge-building and theory-generating qualitative systematic reviews. Journal of Advanced Nursing, 
69(1), 194-204. https://doi.org/10.1111/ j.1365-2648.2012.06037.x

Gonulal, T. (2019). The use of instagram as a mobile-assisted language learning tool. Contemporary Educational Technology, 10(3), 309-323. https:// doi.org/10.30935/cet.590108

Gulati, R. R., Reid, H., \& Gill, M. (2020). Instagram for peer teaching: opportunity and challenge. Education for Primary Care, 31(6), 382-384. https://doi.org/1 $0.1080 / 14739879.2020 .1811163$

Kurniati, E. \& Rusfandi, R. (2021). The Use of Slang on EFL Students' Instagram Statuses: Do They Perceive It Essential? In The 2nd Annual Conference on Social Science and Humanities (ANCOSH 2020), 2, 106-109

Lai, C., Hu, X., \& Lyu, B. (2018). Understanding the nature of learners' out-of-class language learning experience with technology. Computer Assisted Language Learning, 31(1-2), 114-143. https://doi. org/10.1080/09588221.2017.1391293

Lambton-Howard, D., Kiaer, J., \& Kharrufa, A. (2020). 'Social media is their space': student and teacher use and perception of features of social media in language education. Behaviour \& Information Technology, 40(16), 1700-1715, DOI: 10.1080/0144929X.2020.1774653

Messner, M., Medina-Messner, V., \& Guidry, J. (2016). Global health and social media: using Instagram and Twitter in an open online class for global service-learning projects. Communication Teacher, 30(4), 185-189. https://doi.org/10.1080/17404 622.2016.1219042

Nurhikmah, Z. (2021). The Effectiveness Of Media Instagram Toward The Students Speaking Skills at Islamic Institute Sunan Kalijoga Malang. LangEdu Journal, 10(5), 1-16
Rajani, F.R., \& Chalak, A. (2021). A SWOT Analysis of Instagram English Teaching Pages. Journal of Foreign Language Teaching and Translation Studies 6(3), 25-44. https://doi.org/10.22034/ efl.2021.297627.1111

Rinda, R. K., Novawan, A., \& Miqawati, A. H. (2018). Students' perspectives on social media-based learning of writing through Instagram. Journal of English in Academic and Professional Communication JEAPCo, 5(1). 23-33

Rosyida, E. M., \& Seftika, S. (2019). Instagram As Social Media For Teaching Writing. Journal of English Language Teaching and Applied Linguistics, 5(1), 60-70 https:// doi.org/10.26638/js.831.203X

Sallamah, B. I., \& As Sabiq, H. A. (2020). Does Instagram as Learning Media Affect Students' Writing Skill on Recount Text?: An Experimental Research. Journal of Research and Innovation in Language, 2(3), 129-133

Sari, F. M., \& Wahyudin, A. Y. (2019). Undergraduate Students' Perceptions toward Blended Learning through Instagram in English For Business Class. International Journal of Language Education, 3(2), 64-73. https://doi. org/10.26858/ijole.v1i1.7064

Soviyah, S., \& Etikaningsih, D. R. (2018). Instagram Use To Enhance Ability In Writing Descriptive Texts. Indonesian EFL Journal, 4(2), 32. https://doi. org/10.25134/ieflj.v4i2.1373 